\section{An unusual case of migration of an esophageal stent for benign esophageal stricture}

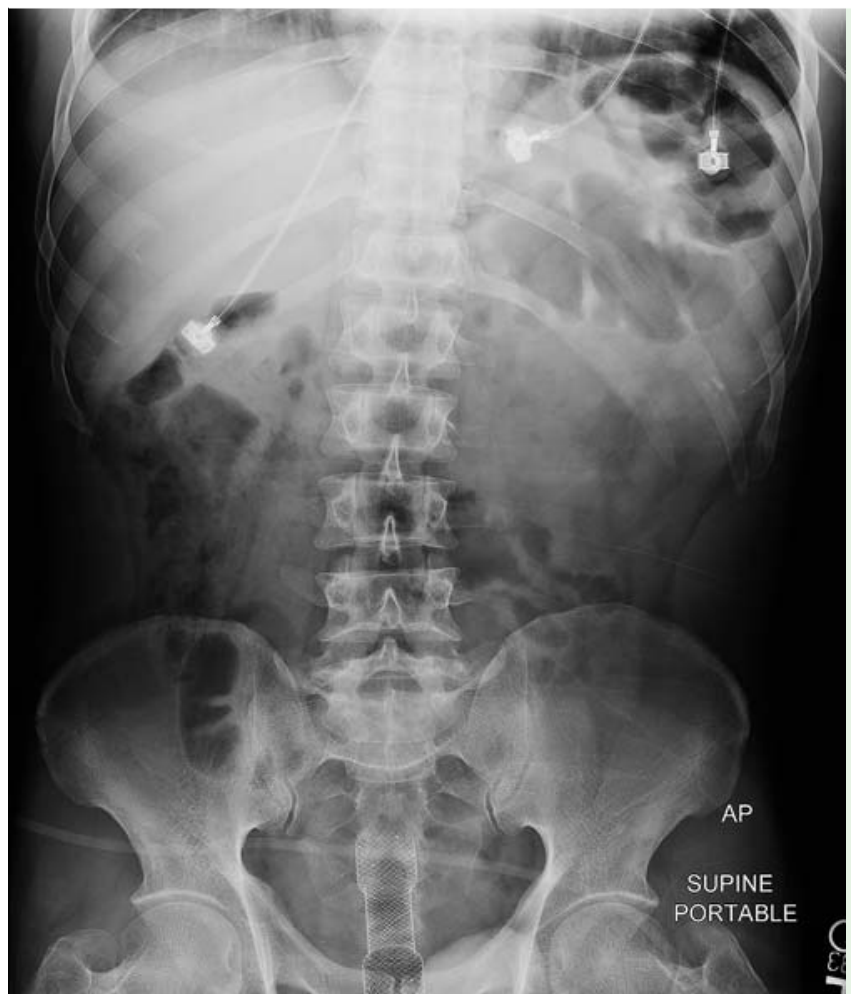

Fig. 1 Abdominal radiograph showing the stent within the pelvis.

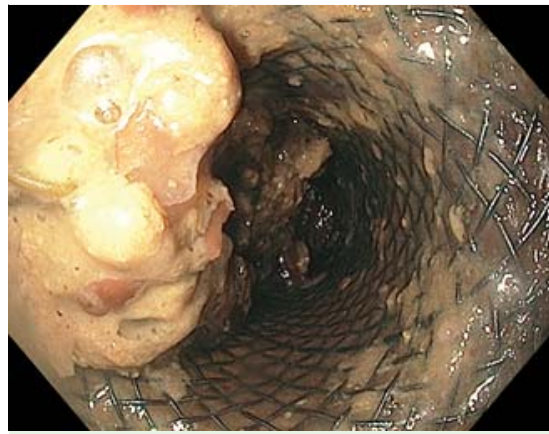

Fig. 2 Sigmoidoscopic view showing the esophageal stent that had migrated into the rectum.

A 38-year-old Hispanic man with a benign esophageal stricture presumed to be related to chronic acid exposure or toxic ingestion was treated with recurrent esophageal balloon dilations for refractory symptoms and eventually underwent esophagectomy with gastric pull-up and pyloromyotomy. His postoperative course was complicated by recurrent strictures at the esophagogastric anastomosis despite multiple dilations. A subsequent esophagogastroduodenoscopy demonstrated a benign-looking stricture. This was tra-

Fig. 3 The esophageal stent following its removal from the rectum.

versed after balloon dilation and a fully covered self-expandable metal stent (FCSEMS) was placed.

The patient experienced complete resolution of his dysphagia following FCSEMS placement; however, he did not attend for the stent removal procedure at 6 weeks. He presented back to clinic 12 weeks after stent placement with complaints of rectal pain and tenesmus. Abdominal radiography showed that the esophageal stent had migrated into the pelvis ( $\mathbf{F i g . 1}$ ). Rectal examination was notable for a palp- able endoprosthesis. Flexible sigmoidoscopy was performed with extraction of the stent using rat-tooth forceps ( $\bullet$ Fig. 2 and Fig.3). A localized area of erythematous mucosa related to stent trauma was identified within the rectum.

Endoscopic esophageal stent placement for benign refractory strictures has evolved to provide long-term symptom control and relief of dysphagia in $90 \%$ of patients $[1,2]$. Stent migration is the most frequently recognized complication encountered following placement of FCSEMSs for this indication, occurring in $25 \%-39 \%$ of patients [2,3]. Stent anchoring techniques using clips, over-thescope clips, or suturing devices to fix the upper flare of the stent have been shown to significantly decrease migration rates to as low as $13 \%-16 \%[4,5]$. Extraction of migrated stents to prevent hemorrhage, perforation, or obstruction related to stent impaction is advocated.

The current case report describes a rare complication of an esophageal stent, namely migration through the entirety of the gastrointestinal tract and into the rectum. Although the majority of stents become entrapped within the stomach, the presence of a pyloromyotomy in our patient may have predisposed to distal migration of the stent $[6,7]$. Prompt recognition and treatment of migrated stents may help to decrease stent-related adverse events.

\section{Endoscopy_UCTN_Code_CPL_1AH_2AJ}

Competing interests: Bryan G. Sauer has received research support for ongoing Esophageal Stent study from Cook Medical.

Justin M. Gomez has no conflict of interest to disclose.

\section{Justin M. Gomez, Bryan G. Sauer}

Division of Gastroenterology and Hepatology, University of Virginia Health System, Charlottesville, Virginia, USA

\section{References}

1 ASGE guideline 2014. The role of endoscopy in the evaluation and management of dysphagia. Gastrointest Endosc 2014; 79: 191

2 Buscaglia J, Ho S, Stenvens P et al. Fully covered self-expandable metal stents for benign esophageal disease: A multicenter retrointest Endosc 2011; 74: 207-211

3 Senousy B, Gupte A, Draganov P et al. Fully covered Alimaxx esophageal metal stents in the endoscopic treatment of benign esophageal diseases. Dig Dis Sci 2010; 55: $3399-$ 3403 spective case series of 31 patients. Gastro- 
4 Mudumbi S, Velazquez-Avina J, Mönkemüller $K$ et al. Anchoring of self-expanding metal stents using the over-the-scope clip, and a technique for subsequent removal. Endoscopy 2014; 46: 1106-1109

5 Vanbiervliet G, Filipii J, Hebuterne X et al. The role of clips in preventing migration of fully covered metallic esophageal stents: a pilot comparative study. Surg Endosc 2012; 26: 53-59

6 An H, Lee H, Chung I et al. Endoscopic removal of a migrated esophageal self-expandable metal stent after compression with detachable snares through an intact esophageal stent. Gastrointest Endosc 2010; 71: $205-$ 207

7 Oh Y, Kochman M. Polyflex esophageal stent migration with elimination per rectum. Gastrointest Endosc 2007; 66: 633

\section{Bibliography}

Dol http://dx.doi.org/

10.1055/s-0042-104277

Endoscopy 2016; 48: E107-E108

(c) Georg Thieme Verlag KG

Stuttgart · New York

ISSN 0013-726X
Corresponding author

Bryan G. Sauer, MD

PO Box 800708

1300 Jefferson Park Ave

Charlottesville

VA 22908-0708

USA

BS2DD@hscmail.mcc.virginia.edu 